\title{
Author Spotlight: Nico Pagano
}

\author{
Nico Pagano ${ }^{1}$
}

Accepted: 5 December 2020 / Published online: 12 January 2021

(c) The Author(s), under exclusive licence to Springer Science+Business Media, LLC part of Springer Nature 2021

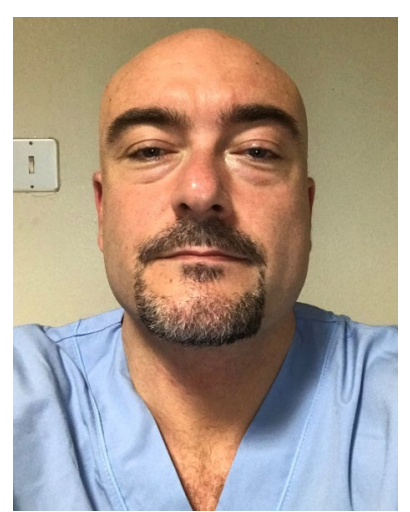

Nico PAGANO, MD (nicopagano@gmail.com), is a gastroenterologist working in the endoscopy unit of Sant'Orsola-Malpighi University Hospital in Bologna.

After graduating at the University of Turin, he specialized in gastroenterology at the same institution under the mentorship of Professor Rizzetto. He joined Professor Repici at the Humanitas Institute in Milan where he developed his advanced endoscopic skills. He visited many international endoscopic units in order to improve his endoscopic education. In 2013, he moved to Bologna to implement endoscopic ultrasound and interventional endoscopy at the Sant'OrsolaMalpighi University Hospital.

$\mathrm{He}$ is a renowned expert in therapeutic endoscopy, having performed several thousand interventional procedures. His fields of interest are diagnostic and interventional endoscopic ultrasound, biliary interventional endoscopy, stenting of the gastroenteric tube, and endoscopic sub-mucosal dissection.

Dr. Pagano is reviewer for many impactful journals and is a member of the editorial board of Techniques in Coloproctology. He has given numerous talks about interventional endoscopy at national workshops and meetings and has published several papers about endoscopic topics. Dr. Pagano is actively involved as a member of the Italian Society of Endoscopy (SIED), the Italian Association for the Study of the Pancreas (AISP), and the Italian Endoscopic Ultrasound Club (EUS-club). He cooperates with the Advanced International Mini-Invasive Surgery (AIMS) Academy in Milan as a mentor for training and education in advanced therapeutic endoscopy.

Publisher's Note Springer Nature remains neutral with regard to jurisdictional claims in published maps and institutional affiliations.

Nico Pagano

nicopagano@gmail.com

1 Sant'Orsola-Malpighi University Hospital, Bologna, Italy 